\title{
Four years on the track of Callinectes sapidus (Rathbun, 1986): reconstructing the invasion of the Iberian Peninsula using social networks sites and citizen science.
}

David Izquierdo Gomez ( $\square$ david.izquierdo-gomez@univ-pau.fr)

University of Pau and the Adour Region https://orcid.org/0000-0002-5054-0465

\section{Research Article}

Keywords: Callinectes sapidus, Mediterranean, Recreational fishery, Online questionnaires, Monitoring invasive species, Local ecological knowledge

Posted Date: March 26th, 2021

DOl: https://doi.org/10.21203/rs.3.rs-195650/v1

License: (9) This work is licensed under a Creative Commons Attribution 4.0 International License. Read Full License 


\section{Abstract}

Callinectes sapidus (Rathbun, 1896) is one of the 100 worst alien invasive species in the Mediterranean Sea, first reported in Venice in 1949. Firstly, the portunid crab colonized the Northern Levantine basin, and half a century later the species spreads rapidly in the Western basin. The general use of social network sites and smart phones have derived in the bloom of citizen science, which enlists the general public in gathering scientific information across large spatio-temporal scales. This research, describes the use of citizen science to unveil the colonization of $C$. sapidus in the Iberian Peninsula, using the Local Ecological Knowledge of recreational fishermen. Overall, $C$. sapidus has been detected in more than 300 locations, including a number of Natura2000 areas and 18 rivers. Eventually, recreational fishermen perceived the presence of the portunid crab as detrimental for the ecosystem.

\section{Introduction}

Callinectes sapidus (Rathbun, 1986), is one of the 100 worst alien invasive species (AIS) in the Mediterranean Sea (Streftaris, N., \& Zenetos, A., 2006). The natural distribution range of the species spans across the Atlantic coast of America, from Nova Scotia to Northern Argentina (Williams, 1974). According to Galil et al. (2002 and references therein), the species was first reported within the boundaries of the Mediterranean Sea in Venice (northern Adriatic Sea), in 1949. The dispersion of C. sapidus in the western Mediterranean basin was not as fast as in eastern zones, where the species colonized a number of areas within decades (Beqiraj and Kashta, 2010; Dulčić et al., 2011; Mancinelli et al. 2013).

Furthermore, the nutritional aspects of the blue crab and its potential harmfulness for consumers has been already studied (Gökoðlu et al. 2003; Türkmen et al. 2006; Ayas \& Ozugul 2011; Zotti et al. 2016) in order to exploit the species commercially, without jeopardizing consumers health (Atar \& Seçer, 2003; Sumer et al. 2013; Daban et al. 2016). In areas where blue crab is naturally distributed, the need of data to manage the stock effectively requires from distribution studies (Sharov et al. 2003). It was not until the early 2010's when C. sapidus was reported in the Iberian Peninsula (Castejón \& Guerao, 2013), and in 2015, ovigerous females of $C$. sapidus were reported in the southeast of Spain (Izquierdo-Gómez \& Izquierdo-Muñoz, 2016). However, it was from spring 2016 when the increasing incidence of blue crab in fisheries landings, rose social awareness in the Iberian Peninsula. Articles in newspapers and pictures of blue crab posted in social networks sites (SNSs), started to mirror the increasing abundances of blue crab along the Iberian coast.

The development of SNSs, broadly used by all age classes of the population world-wide, has led to the bloom of citizen science (CS): research technique that enlists the public in gathering scientific information bringing the opportunity to scientists to sample across large spatio-temporal scales (Bhattacharjee, 2005). The latter brings the opportunity to a community of scientists to turn into a vast source of comprehensive data for other researchers, resource managers, policy makers, educators and, eventually, the broad public all over the world. Few decades ago, the British Trust for Ornithology project 
Garden Bird Watch in the UK, shows how CS can provide large data sets (six million birds sampled) and involve large number of people (circa 400,000) dispersed around a large array of locations (i.e. 228,000; Devictor et al., 2010 and references therein). Despite marine studies based on CS were initially scarce compared to terrestrial studies, Delaney et al. (2008) is a good example where the presence of two alien species (i.e. Carcinus maenas and Hemigrapsus sanguineus) was described using CS. Recently, Giovos et al. (2019), monitored multiple marine invasions stimulating public engagement in the Eastern Mediterranean, in one of the most comprehensive and systematic efforts carried out in the Mediterranean Sea so far.

Despite records of the distribution of $C$. sapidus in the Iberian Peninsula have been recently published and represent valuable information (Fernandez-Guirao, 2013; Izquierdo-Izquierdo-Gómez \& IzquierdoMuñoz, 2016; González-Wangüemert \& Pujol, 2016; Garcia et al. 2018; Fuentes et al., 2019; Morais et al., 2019; Vasconcelos et al., 2019), they mostly consist on isolated records from a local perspective. Thus, there is still a lack of a comprehensive approach addressing the spatio-temporal establishment and dispersion of $C$. sapidus in most of the areas colonized by the portunid species. This research describes 4 years exploring the use of CS and SNSs to describe the invasion of $C$. sapidus in the Iberian Peninsula, based on the Local Ecological Knowledge (LEK) of recreational fishermen. Overall, this work describes the establishment and dispersion of $C$. sapidus in the Iberian Peninsula, using a CS framework. Firstly, this study aimed to detect i) the very first establishment areas of $C$. sapidus and ii) the existence of selfsustained populations. In second term, more thorough goals were envisaged: i) to unravel the spatiotemporal dispersion of $C$. sapidus over the Iberian Peninsula and ii) to quantify the fishermen's concern towards the potential influence of $C$. sapidus in the ecosystem.

\section{Materials And Methods}

\subsection{Study dissemination and data collection}

The data collection in this research evolved apace with the blue crab invasion. In first term, after the detection of Callinectes sapidus in the SE of Spain in 2015 (Izquierdo-Gomez \& Izquierdo-Muñoz 2016), the blue crab presence persisted in spring 2016. Thus, a four-month survey (June 2016 - October 2016), was lunched on Facebook (www.facebook.com), coinciding with the presence of ovigerous females in coastal areas. Recreational fishermen in contact with blue crabs were targeted via Facebook, by posting comments on their photos and/or in the most relevant groups with recreational fisheries interest.

Fishermen were asked to send an orthogonal picture of the captured blue crabs via private messages. The collected data allowed i) to confirm the locations where blue crab was stablished, ii) to determine the sex and the carapace length of each individual and, iii) to detect self-sustainable populations in light of the size structure of the sampled individuals. The presence of the crab in SNSs was further monitored in 2017 and in 2018. In light of the social concern arising from the presence of $C$. sapidus in Catalonia and 
the Valencian community in late summer/autumn 2018, a two-section questionnaire was launched in early 2019 to obtain more specific data (Facebook Survey tool:

https://www.facebook.com/simple.surveys/; Code Rubik inc.). The first group of questions targeted personal information: Question (Q) 1) Facebook name, Q2) home location, Q3) gender, Q4) age, Q5) education background and Q6) the preferred fishing type. In the second section, details on the presence of the crab were asked: Q7) exact location(s) in first year encounter, Q8) year of first contact/sighting, Q9) source of awareness about the presence of blue crab, Q10) temporal incidence of gravid females. Eventually, the respondents were given the option Q11) to express their personal opinion about the presence of the blue crab in the coast, and to score the potential effects of the blue crab on the ecosystem (opinion index). The opinion index had four levels based on the fishermen perception of blue crab influence in the ecosystem (i.e. $4=$ extremely high, $3=$ high, $2=$ mean, $1=$ small) which could have positive (beneficial) or negative sign (hazardous). For instance, a score of -4 meant an extremely negative effect of blue crab on the ecosystem, a score of +2 meant a medium positive effect on the ecosystem. $A$ zero-score meant neutral: no influence of the blue crab in the ecosystem. Differences on the mean opinion index between provinces were assessed by a Kruskal-Wallis test. All formulated questions were open-type, meaning that answers like "Do not know", "Do not answer" or "blank" were available within the choices for the respondents. The questionnaires were spread using well-known groups on Facebook with recreational fisheries interest once per week. The questionnaire was available until December 2019 and the time to complete it was 10-15 minutes.

\subsection{Image analysis}

The carapace length of each crab was measured using a reference object placed by fishermen over/next to each specimen (a ruler or a coin over the carapace was suggested). Non-orthogonal pictures and images without a reference object were discarded. Specialized software (ImageJ; Abràmoff et al. 2004) was used to measure the carapace width of each crab (maximal distance between the posterior anterolateral spines). Crabs were grouped into size classes, namely: small ( $C W<80 \mathrm{~mm})$, medium $(80<$ $\mathrm{CW}<120 \mathrm{~mm})$ and large $(\mathrm{CW}>120 \mathrm{~mm})$ according to Harding (2003). The frequency of the size distribution was determined for each sex.

\subsection{Articles published in regional newspapers as a proxy of blue crab dispersion}

The number and origin of articles published in local newspapers were used as a proxy to cross-validate the results of the spatio-temporal distribution of $C$. sapidus obtained from Q7 and Q8. At a province level, the mean first-year presence of blue crab declared by respondents, was correlated with the year when the 
crab presence was first documented in local newspapers. Systematic online searches including "blue crab" + the Boolean operator "AND" + the province name (e.g. "blue crab" AND Alicante) were performed with Google Chrome browser (https://www.google.com/chrome/) in the search engine www.google.com. The advance search settings were configured to perform the searches i) in Spanish language and ii) within the Spanish territory for each year of the study period $(2010-2019)$.

\section{Results}

\subsection{Establishment of Callinectes sapidus}

A total of 159 pictures of $C$. sapidus were sent from 26 different fishermen (Fig. 1). The captures of blue crabs were mostly reported in Tarragona (Ebro Delta river, $n=42$ ), Alicante (Guardamar, $n=36$ ) and Valencia (Gola del Perellonet, $n=34$; Estany de Cullera, $n=34$ ). To a lesser extent, captures from Castellón (Gola de Nules; $n=10)$, Murcia $(n=2)$ and Gandia $(n=1)$, were reported. The crabs from Alicante were mostly captured in marine waters, whereas the crabs reported from Valencia, Castellon and Cullera were so in fresh/brackish waters (mostly at channels and brackish waters of the Albufera de Valencia, Estany de Nules and Estany de Cullera respectively). In Tarragona, crabs captured in salt waters were either reported by recreational or professional fishermen, whereas, the crabs captured in fresh/brackish waters were reported exclusively by recreational fishermen.

The maximum and minimum carapace lengths resulted $9.73 \mathrm{~cm}$ (female, Guardamar) and $22.8 \mathrm{~cm}$ (male, Cullera; Table 1). The maximum carapace length range was detected in Cullera males (range $=9.9 \mathrm{~cm}$ ) whereas the minimum range value was registered in males from Castellón $(4.91 \mathrm{~cm}$; Fig. 2). The vast majority of the crabs reported from Alicante ( $92 \%)$, were captured by professional fishermen in sea water, and $95 \%$ of them were females $(\nabla / \nabla=68 / 4)$. On the other hand, the least proportion of females was registered in Cullera $(\nabla=26 \%$ ), where, all the crabs were captured by anglers in brackish waters (Estany de Cullera). According to Harding (2003), a total of $80.7 \%$ of the crabs showed large sizes, $19.3 \%$ showed medium sizes, whereas, no small individuals were reported. Several tilted pictures and/or containing multiple crabs into a bucket/sink were used internally to support the trends of male/female ratios, incidence of gravid females and capture locations obtained from exploitable orthogonal pictures.

\subsection{Dispersion of Callinectes sapidus}

\subsubsection{Characterization of respondents}

The questionnaire posts were seen by a total of 2893 Facebook users, and 1068 did open the link (click conversion $=36.9 \%$ ). The participants in the study are hereafter referred as respondents. Either blank 
questionnaires or questionnaires with less than $80 \%$ of the questions completed were removed (450 responses). The Facebook survey application detected 18 Facebook users filling the questionnaire more than once, therefore, the less complete attempt of each Facebook user was removed prior to data analysis. The responses received from Spanish provinces not belonging to the Mediterranean Sea or to the Atlantic Andalucía (i.e. Huelva, Sevilla and Cadiz) were removed from the analysis (47 responses removed; Fig. 1 Annex). Eventually, a subset of 553 responses were kept for the final analyses. Although, the results are mostly expressed at a province level throughout the text, data could be referred to a Community level, in order to ease the reading of the manuscript. For clarification, a community is a larger administrative organization than province or city, but smaller than country (i.e. Country > Community > Province $>$ City).

\subsubsection{Origin of the respondents}

The respondents from the Valencian Community contributed the most to the study (Alicante, Castellón and Valencia; total $=35.9 \%$; Fig. 3). Intermediate values of participation were registered for Andalucía (Almería, Cadiz, Huelva, Granada, Málaga and Sevilla; total $=24.3 \%$ ) and Catalonia (Barcelona, Girona and Tarragona; total $=23.3 \%)$. Eventually, Baleares $(9.8 \%)$ and Murcia $(4.9 \%)$ registered the lowest participation of all Spanish communities. Remarkably, respondents from the Algarve region (South of Portugal) also participated in the study (1.8\%). Nine women answered the questionnaire (1.62\%), the rest of the participants were men. The mean age of the respondents per province ranged between $40.6 \pm 13.7$ years and $31 \pm 6.1$ years, with no significant differences between provinces $(H=17.81, p$-value $=0.22$; Fig.2 in Annex).

\subsubsection{Type of fishing}

Angling was the most preferred type of fishing (range: $73.7 \pm 18 \%$ ) within the respondents, but in the case of Granada, were most of the respondents practiced spear-fishing (60\%). The only provinces which did not show spear fishermen within the respondents, were Algarve and Sevilla. Professional fishermen from Baleares, Murcia, Castellon and Girona did not contribute to this study. A total of 42 responses $(7.3 \%)$ showed blank and $14(2.4 \%)$ declared not to practice any fishing activity. 


\subsubsection{Sources of knowledge about the presence of C. sapidus}

Most of the respondents acknowledged the presence of $C$. sapidus due to fishing encounters/sightings (Fig. 4), with proportions ranging between $71 \%$ and $35 \%$. Sightings (on land or diving) was the next reason why respondents aware of the presence of the portunid crab in their fishing areas. Remarkably, $50 \%$ of the respondents from Tarragona are aware of the presence of $C$. sapidus because they had seen the crab (not captured). The least proportion of respondents knew about the presence of the crab in their areas via newspapers. Most of the respondents from the SE of Andalucía (i.e Almería, Granada and Málaga) declared the portunid crab as absent in their areas (Fig. 4). A detailed list of the online articles used in this study is available at (https://osf.io/nk3ph/).

\subsection{Distribution of Callinectes sapidus}

\subsubsection{Spatial distribution}

A subset of 400 respondents provided a total of 661 locations where the blue crab was present in the Iberian Peninsula. A total of 304 unique locations were identified and geolocated in a map (e.g. beach of Pinet, mouth of the Segura river) (Fig. 5). Most of the mentioned locations belonged to the province of Valencia (20.4\%), Castellón (18\%), Tarragona (17.1\%), Alicante (14.2\%) and Baleares $(7.1 \%)$, whereas the least number of locations belonged to Almería $(0.5 \%)$ and Sevilla $(0.3 \%)$. Locations from Barcelona (5.9\%), Cadiz (5.3\%), Girona (3.9\%), Huelva (2.7\%) Murcia (2.6\%) and Algarve (2\%), showed intermediate proportions (Fig. 5). A complete list of the georeferenced records of $C$. sapidus is available at (https://osf.io/nk3ph/).

\subsubsection{Temporal distribution}

A total of 340 respondents, answered a specific year to the question Q8. Respondents from the provinces of Castellon (18.5\%), Tarragona (18.2\%), Valencia (16.5\%) and Alicante (15.3\%), contributed the most to Q8, whereas, Baleares (6.8\%), Barcelona (5.3\%), Cadiz (5\%), Girona (5\%), Murcia (3.5\%), Huelva (2.6\%), Algarve (2.4\%), Sevilla (0.6\%) and Almería altogether (0.6\%), gathered around $25 \%$ of the participation to this section. Provinces with low participation, showed higher proportions of "Do not know" and "blank" responses. Based on the obtained results, $C$. sapidus appeared in the Iberian Peninsula for the first time in 
Tarragona in 2010 (Fig. 6). In the following years, the portunid crab dispersed westwards, to Castellón and Valencia in 2012. Throughout 2013, the crab continued to disperse westwards to Murcia and Alicante. The first eastwards dispersion of the blue crab took place in 2014, with Balearic Islands and Girona being invaded. In 2015, the crab colonized the province of Barcelona, while Cádiz and Huelva provinces were invaded in 2016. The Algarve region resulted colonized in 2017. In Almeria, the blue crab was first detected in 2019, whereas, the presence of the portunid crab was neither declared by respondents from Málaga nor Granada. In Sevilla, the crabs were inconsistently reported from 2015 (Fig. $6)$.

\subsubsection{Validation of the dispersion of $C$. sapidus in the Iberian Peninsula using the temporal distribution of in newspapers as a proxy.}

The first article in the Spanish press declaring the presence of $C$. sapidus in the Iberian Peninsula was published in 2013 in the province of Tarragona, followed by Valencia in 2014 (Fig. 7). Newspapers from Alicante $(n=1)$ and Murcia $(n=6)$ reported the presence of the portunid crab in 2015, whereas, from Barcelona $(n=1)$, Castellon ( $n=1)$ and Huelva, publications came to light in $2017(n=1)$. Moreover, it was not until 2018 when newspapers of Cadiz and Sevilla informed about the blue crab presence; at that time, more than $75 \%$ of the provinces had already published information about the crab invasion.

Eventually, the Balearic Islands reported the portunid crab in the newspapers in 2019 . Circa $30 \%$ of the articles were published in $2018(n=33)$ and 42\% in $2019(n=42)$. The mean colonization year based on respondents and the first-year publication in local newspapers were significantly correlated $(R=0.72, p=$ $0.012, R^{2}=0.52$; Fig. 8).

\subsubsection{Opinion index}

A total of 395 respondents contributed with a score to evaluate the influence of blue crab in the ecosystem. Castellón (-3.29 \pm 0.57 ; mean opinion index \pm SD) and Tarragona $-3.09 \pm 0.98)$ showed the most negative scores, as respondents declared that the portunid crab poses a high risk for the ecosystem (i.e. mean level = -3) (Fig. 9). Overall, the general trend observed in all provinces resulted a negative mean opinion index in the opinion scale (i.e. -4 to 4), with values ranging between -3.29 (i.e. Castellón, high negative impact to the ecosystem) and -1.71 (i.e. Granada, medium negative impact to the ecosystem). Differences in mean opinion index at a province level were not detected (Kruskal-Wallis chi-squared = 
$1.8182, \mathrm{df}=6, \mathrm{p}$-value $=0.9356 ;$ Fig. 9$)$. A total of nine respondents $(2.3 \%)$ considered the blue crab invasion as positive for the ecosystem.

\section{Discussion}

Early detection of IAS has been recognized by invasion biologists to increase the probability of its successful eradication (US Congress OTA 1993; Myers et al. 2000; Delaney 2008 and references therein). The present research describers how CS combined with SNSs resulted a sound approach i) to detect the initial establishment of self-sustainable populations of $C$. sapidus in the Balearic Sea, ii) to describe the presence of $C$. sapidus all over the Iberian Peninsula from Catalonia until northern Portugal, iii) to unveil the 10-year spatio-temporal dispersion of the species from 2010, and iv) to assess the perception of recreational fishermen on the presence of $C$. sapidus as detrimental for the ecosystem. Overtime and in first term, $C$. sapidus colonized the Ebro delta river and dispersed southwards all over the mainland coast of the Balearic sea until the Mar Menor (border between Alicante and Murcia region). In second term, the species colonized North-Eastern areas of Catalonia (i.e Barcelona and Girona) and the Balearic Islands. Eventually, the portunid crab invaded the south of the Iberian Peninsula, including Atlantic areas as Cadiz, Huelva and Algarve in Portugal. A number of protected Natura2000 areas showed colonized, as well as, a number of freshwater ecosystems (rivers, channels, marshes and lagoons).

Delaney et al. (2008) stated that an excess of information or tasks to accomplish might result in issues concerning the endurance of citizen scientists' patience which might be detrimental for the study. This is why the present study, in 2016, pursued to unveil the blue crab colonization of the coast with a simple specific request: to send an orthogonal picture of captured blue crabs. Arguably, the wide range of carapace lengths ( 9 to $21 \mathrm{~cm}$ ) and the co-occurrence of ovigerous females in several areas of the Levantine coast of Spain separated by tenths to hundreds of kms (e.g. Alicante, Cullera, Castellón), point towards an establishment of self-sustainable populations of blue crab, at least from 2016. From the results obtained in 2016, the presence of $C$. sapidus was detected along $430 \mathrm{~km}$ along the Spanish shoreline, from Ebro Delta river (Tarragona) to Mar Menor (Murcia). Although an active dispersion of adult individuals is possible at a range of hundreds of kilometres (Van Engel, 1958; McConaugha, 1983; Hines et al., 1987) local movements $(1-10 \mathrm{~km})$ prior to long migrations to attain the spawning grounds have been described (Turner et al. 2003). The latter seems to correspond to a migratory behaviour at a large scale which is not yet studied in the Mediterranean Sea, but it could be the case in Delta Ebro river and Guadalquivir river, as blue crabs are captured by trawlers off the coast. There is no sound information yet on spawning migrations/areas of $C$. sapidus in Western-Mediterranean, and weather the provenance of the ovigerous females found along the coast is local or regional is still uncertain. However, the presence of overwintering individuals in freshwater environments, together with ovigerous females simultaneously declared in several areas, might point towards a scenario where multiple population sources exist, separated by several tens to hundreds of kilometres (e.g. from north to south: Ebro delta river, Estany de Nules, Estanys d'Almenara, Albufera de Valencia, Jucar river, Marjal de Pego-Oliva, Estany 
de Cullera, Segura river and Mar Menor). Fresh water bodies are present in all the aforementioned locations, and salt water captures were mostly females. Tankersley et al., 1998, described a seaward migration of blue crab females from low-salinity areas of estuaries to spawn near the entrance, and it seems to apply also to western Mediterranean areas. A number of Natura2000 areas resulted colonized by the blue crab, with special ecological concern to Ebro delta river, Albufera de Valencia, Doñana and the whole coastline of the Balearic Islands. Similarly, a total of 18 rivers resulted invaded by the portunid crab, namely: river Antas, Barbate, Belcaire, Bullent, Ebro, Fluviá, Guadalete, Guadalquivir, Guadiana, Jara, Júcar, Llobregat, Piedras, San Pedro, Seco, Serpis, Tinto and Vaca. In some cases, blue crab individuals were found several km upstream. Remarkably, two respondents declared the presence of $C$. sapidus in the "Assut of Xerta" (dam of Xerta; lat: $40.924^{\circ} \mathrm{N}$; lon: $0.492^{\circ} \mathrm{E}$ ), which is located more than $50 \mathrm{~km}$ upstream from the Ebro delta river mouth. Moreover, one respondent declared the presence of blue crab in Flix (further upstream than Xerta; lat: $41.228^{\circ} \mathrm{N}$; Ion: $0.544^{\circ} \mathrm{E}$ ). Despite one respondent from Xerta assured that $C$. sapidus would have been distributed further upstream if the dam had not been present, the presence of blue crab in Flix should be further confirmed. A similar scenario occurs in the Guadalquivir river where crabs have been declared in fresh water zones, several kilometres upstream.

The spatio-temporal dispersion of $C$. sapidus all over the Mediterranean coast of the Iberian Peninsula started in the Ebro delta river in 2010s. The further dispersion can be divided in three stages: colonization of i) the mainland coast of the Balearic Sea (Valencia, Alicante and Northern Murcia in 2015-2016), ii) the Balearic Islands and Northern Catalonia (2017-2018) iii) the Atlantic Andalusia/Algarve and Aveiro regions (2018-2019). Surprisingly, there were two respondents declaring the presence of the portunid crab in Aveiro region (Northern Portugal). Although the establishment of the crab in the English Channel have been described (Pezy et al., 2019), the potential presence of $C$. sapidus in Aveiro might respond to an incipient colonization, due to dispersion from the south east of the Iberian Peninsula, which have been declared as a hot-spot for invasions of decapod crustaceans, including $C$. sapidus (González-Ortegon et al., 2020). Prior to the recent blue crab colonization of the Iberian Peninsula, the presence of the portunid crab was reported in Atlantic waters as in the Sado estuary in Lisbon, (Ribeiro and Veríssimo, 2014), Galician waters (Bañon et al., 2016) or Gijon (Cabal et al., 2006). However, self-sustainable populations of blue crab seem not to have established in these areas, as all respondents from Galicia and Asturias taking part in the present study declared an absence of blue crab in their fishing areas. Whether the presence of the blue crab in Lisbon, Galicia or Gijon was due to larval transport in ballast waters or to a man-mediated introduction, is hard to say. However, given the distance and isolation of the aforementioned reports from the current stable populations, the possibility of migrant individuals is discarded. The blue crab dispersion described in this study, agrees with the registers published in scientific journals; the first blue crab detection in the Mediterranean coast of Spain occurred in Ebro delta river in 2013 (Fernandez-Guirao, 2013; Ebro Delta river), followed by the mouth of Segura river in Guardamar in 2016 (González-Wangüemert \& Pujol, 2016; Izquierdo-Izquierdo-Gómez \& IzquierdoMuñoz, 2016), the Balearic Islands in 2018 (Garcia et al. 2018), the northern Calalonia (Fuentes et al., 2019), the Atlantic Andalusia and the Algarve region in Portugal in 2019 (Morais et al., 2019; Vasconcelos 
et al., 2019). Such colonization pattern, agrees with the coastal dynamics in the Balearic Sea, where the main current descends along the coast in south-west direction (Maillot \& Taupier-Letage, 2005).

Therefore, the water current transport of eggs and larvae seems the main driver of natural dispersion and colonization of blue crab in the Levantine coast of Spain. This is supported by the delayed colonization of northern provinces of Catalonia (i.e. Barcelona, Girona), closer to Ebro delta river compared to southern locations of the Balearic Sea (i.e. Valencia and Alicante). Interestingly, the presence of $C$. sapidus was barely declared between the coast of Malaga and Murcia. The latter indicates that, once the blue crab established in the mainland coast of the southern Balearic Sea (Guardamar - Mar Menor), a consecutive dispersion to the adjacent biogeographic area of the Alboran Sea and the Atlantic Algarve region did not occur. The Almerian front is formed when the current descending form the Balearic Sea encounters an ascending current driven from the entrance of Atlantic waters into the Alboran Sea (Siokou-Frangou et al., 2010). Thus, the Almerian front together with the characteristic clockwise gyres in the Alboran Sea, could hinder the coastal dispersal of eggs and larvae delaying the colonization of sedimentary habitats in the south of the Iberian Peninsula. The absence of the portunid crab in Malaga, Granada, Almeria and southern Murcia could be related to the low abundance of estuarine habitats with salinity gradients, needed by $C$. sapidus to complete its life cycle: fresh water bodies to overwinter (specially males and juveniles), brackish waters to mate and high salinity waters to spawn (Tankersley et al., 1998; Hines et al., 2008). All over the coast of the aforementioned provinces, sedimentary habitats linked to fresh water discharges are seldom, and temperatures are lower than in the Balearic Sea due to the influence of Atlantic waters (Templado et al., 2009). Nehring (2011) pointed towards too low water temperatures as an important factor for the non-establishment of $C$. sapidus in northern Europe and in the Black Sea, and it could be the reason why $C$. sapidus is not as widely distributed as in other areas of the Iberian Peninsula. Interestingly, the aforementioned provinces showed i) a lower number of respondents, ii) a lower number of published articles in newspapers about the presence of $C$. sapidus and iii) a higher proportion of respondents declaring the species as "absent" in their fishing areas. Arguably, it can be stated that in areas where $C$. sapidus is less abundant or absent, the Facebook posts might neither elicit the participation in the study nor the publication of information in newspapers, due to the lack of social concern. The same scenario of an incipient colonization of the area, seems to occur in the Adriatic Sea in 2019 , where only $10 \%$ of the respondents declared the presence of $C$. sapidus (Cerri et al., 2020).

Therefore, the colonization of Cadiz, Sevilla, Huelva, Algarve and Aveiro, seem to be still incipient, when this study was carried out. Due to the high potential of colonization of $C$. sapidus, the areas between Malaga and Murcia are still expected to be colonized, in fact, sightings have been already declared in lagoons and fresh water environments of Almeria province (i.e. Vera). However, whether it is the incipient colonization or just an isolated sighting of dispersal individuals is hard to ascertain.

CS may provide valuable resources and data for scientists, as well as, strengthen monitoring programs, boost collaboration, and promote education (Bonney et al. 2009). It is true that a number of short notes reporting the presence of $C$. sapidus have been recently published, however, it consists in a corpus of isolated documents merely describing the presence of $C$. sapidus at a local level. The present research is 
one of the few exploring the distribution of $C$. sapidus via CS and SNSs, together with Cerri et al., (2020), and the only one describing the colonization of a Mediterranean region from a spatio-temporal perspective. Additionally, this approach pin pointed the actual distribution of blue crab in the Iberian Peninsula with 661 locations from Northern Catalonia until Aveiro, including the Balearic Islands, most of them being new records. Cerri et al. (2020) successfully described the geographical distribution of $C$. sapidus in Italy and adjacent countries via on-line questionnaires, concluding an early state of the colonization process. From the results of this study, the colonization process can be considered as advanced in the Balearic Sea, intermediate in Algarve and Atlantic Andalucia, while in the Mediterranean Andalucia and Northern Portugal might not have started yet. Throughout the Iberian colonization process, the time lapse between the first detection of the portunid crab and the mean year of publication of the articles in newspapers, seem to reduce. This can be explained by a stronger dispersion pressure of $C$. sapidus in shape of larger numbers of migrating individuals and/or drifting eggs/larvae, as the number of colonized areas raises. From perspective of the media, due to the steady colonization process of blue crab, non-invaded areas could be potentially colonized, and this might explain the quicker reaction of media when reporting the first sighting of the portunid crab. Nowadays, in globalized societies connected via SNSs and smartphones, anglers and media from a non-invaded area can be easily aware of the social concern rose by the presence of blue crab. Although the Spanish media has largely reported the colonization of blue crab, the anglers taking part in this study declared to be aware of the presence of the portunid crab mostly due to direct encounters when fishing and not via newspapers. Tarragona, the first province where $C$. sapidus was detected (Ebro delta river), showed the largest proportion of non-fishing sightings which could be explained by the high abundance of the portunid crab. Thus, an indicator of an advanced stage of blue crab colonization could be the proportion of respondents whose first contact with C. sapidus was while walking or diving. From an ecological perspective, the high abundances of blue crab together with its territorial behaviour (specially males in fresh water areas), would force some individuals to remain in exposed areas next to the river margins, easily spotted by walkers and/or fishermen on its way to their fishing spots. Despite the eradication of $C$. sapidus has already been considered unfeasible, management measures could mitigate the impact on the ecosystem and help to integrate the species in the socio-economic paradigm (Mancinelli et al., 2017b and references therein). As in other Mediterranean countries, Spanish authorities and decision makers have implemented management plans for the exploitation of $C$. sapidus i) to mitigate the dispersion of the species and ii) to increase economic profit of fishermen, due to the commercial value of the portunid crab (e.g. Cataluña and Baleares). However, the economic profit derived from the exploitation of $C$. sapidus by professional fishermen, recreational fishermen might not be allowed to capture the species and they perceive the portunid crab as detrimental for the ecosystem. Although it has not been analysed in this manuscript, the personal opinion of respondents was also recorded and the main concerns seem to be that the portunid crab i) cuts the fishing lines, ii) destroys the lures and the fishing hooks and iii) predates over autochthonous species affecting the whole ecosystem. Mancinelli et al. $(2013,2017 a)$ described that $C$. sapidus can vary its energy sources in relation with season, environmental conditions, and ontogenetic stage, affecting the benthic food web at multiple trophic levels, by preying on primary consumers as well as on macroalgae and vascular plants. Recently, Prado et al., (2020), described a predatory preference of C. sapidus for blue 
mussel (Mythylus galloprovincialis) and apple snail (Pomacea maculata) compared to other bivalves of the Ebro delta zone, which jeopardizes de shellfish industry. None of the respondents referred to Portunus segnis, and although this species is colonizing new areas in the Mediterranean Sea (Shaiek et al., 2020), it seems to be absent in the Iberian Peninsula.

\section{Conclusion}

The information obtained in this study highlights the value of recreational fishermen as a social guild to involve in CS projects addressing marine AIS issues. The synergy between CS, online questionnaires and SNSs have demonstrated its potential to obtain valuable LEK from anglers; this research represents the most comprehensive and complete description of the establishment and dispersion of blue crab in the Iberian Peninsula context over time. In the Iberian paradigm, once the distribution of blue crab was thoroughly described, further research unveiling the environmental effects of blue crab urge, i) specially in Natura2000 areas and ii) on the potential negative consequences of the portunid crab in fisheries and aquaculture. It is worth to highlight that data quality is paramount in science, and mistaken/biased results arising from CS might have negative environmental, social, and/or political implications (Engel \& Voshell, 2002). Therefore, standardizing monitoring protocols, field-tested with citizen scientists working under realistic conditions is the ideal scenario to maximize data quality and future CS projects involving coastal areas. Moreover, complementary in situ studies are recommended, from an ecological, economic and social perspective, in order to develop better integrated approaches to manage the $C$. sapidus invasion, and potential AIS colonisations in a future to come. The information provided by this study is valuable for managers and stakeholders to achieve the European Commission goal to develop their own fisheries and aquaculture regulations, ensure a sustainable practice (http://ec.europa.eu/fisheries/cfp/eff/national_plans/index_es.htm), and to carry out a comprehensive analysis of introduction pathways of invasive species, stated in the Article 11 of the new European Regulation on invasive species (EU n. 1143/2012). Despite, management plans to commercially exploit $C$. sapidus have been already implemented (e.g. Balearic Islands and Cataluña), further studies to mitigate predation in shellfish cultures are strongly recommended to guarantee the sustainability of this industry. Additionally, further research is needed in order to unveil potential negative influences of $C$. sapidus on other commercially important species as caramote prawn (Melicerthus kerathurus), European eel (Anguila anguila) or the common octopus (Octopus vulgaris).

\section{Declarations}

\section{Data Availability Statements}

All data supporting the findings of this study are available in OSF repository in the following address: https://osf.io/nk3ph/

\section{Declaration of interests}


The authors declare that they have no known competing financial interests or personal relationships that could have appeared to influence the work reported in this paper.

\section{References}

Abràmoff, M. D., Magalhães, P. J., Ram, S. J., 2004. Image processing with ImageJ. Biophotonics international, 11, 36-42.

Atar, H. H., Seçer, S., 2003. Width/length-weight relationships of the blue crab (Callinectes sapidus Rathbun 1896) population living in Beymelek Lagoon Lake. Turkish Journal of Veterinary and Animal Sciences, 27, 443-447.

Ayas, D., Ozogul, Y., 2011. The effects of sex and seasonality on the metal levels of different muscle tissues of mature Atlantic blue crabs (Callinectes sapidus) in Mersin Bay, north-eastern mediterranean. International journal of Food science \& technology, 46, 2030-2034.

Bañón, R., Cuesta, J.A., Almon, B., Pérez-Dieste, J., Trigo, J.E. and Ríos, M.B., 2016. First record of two decapod crustaceans, the caramote prawn Penaeus kerathurus and the blue crab Callinectes sapidus from Galician waters (NE Atlantic).

Beqiraj, S., Kashta, L., 2010. The establishment of blue crab Callinectes sapidus Rathbun, 1896 in the Lagoon of Patok, Albania (south-east Adriatic Sea). Aquatic Invasions, 5, 219-221.

Bhattacharjee, Y., 2005. Citizen scientists supplement work of Cornell researchers: a half-century of interaction with bird watchers has evolved into a robust and growing collaboration between volunteers and a leading ornithology lab. Science, 308, 1402-1404.

Bonney, R., Cooper, C. B., Dickinson, J., Kelling, S., Phillips, T., Rosenberg, K. V., Shirk, J., 2009. Citizen science: a developing tool for expanding science knowledge and scientific literacy. BioScience, 59, 977984. 
Cabal, J., Millán, A.P. and Arronte, J.C., 2006. A new record of Callinectes sapidus Rathbun, 1896 (Crustacea: Decapoda: Brachyura) from the Cantabrian Sea, Bay of Biscay, Spain. Aquatic Invasions, 1(3), pp.186-187.

Castejón, D., Guerao, G., 2013. A new record of the American blue crab, Callinectes sapidus Rathbun, 1896 (Decapoda: Brachyura: Portunidae), from the Mediterranean coast of the Iberian Peninsula. Biolnvasions Records, 2, 141-143.

Cerri, J., Chiesa, S., Bolognini, L., Mancinelli, G., Grati, F., Dragičević, B., ... Azzurro, E., 2020. Using online questionnaires to assess marine bio-invasions: A demonstration with recreational fishers and the Atlantic blue crab Callinectes sapidus (Rathbun, 1986) along three Mediterranean countries. Marine Pollution Bulletin, 156, 111209.

Daban, I. B., Cengiz, O., Tuncer, S., 2016. Further range expansion of the blue crab Callinectes sapidus (Rathbun, 1896) (Crustacea: Decapoda: Brachyura) in Turkish waters, Northern Aegean Sea: insight into distribution depth. Cahiers de Biologie Marine, 57, 175-178.

Delaney, D. G., Sperling, C. D., Adams, C. S., Leung, B., 2008. Marine invasive species: validation of citizen science and implications for national monitoring networks. Biological Invasions, 10, 117-128.

Devictor, V., Whittaker, R. J., Beltrame, C., 2010. Beyond scarcity: citizen science programmes as useful tools for conservation biogeography. Diversity and distributions, 16, 354-362.

Dulčić, J., Tutman, P., Matić-Skoko, S., Glamuzina, B., 2011. Six years from first record to population establishmen t: the case of the blue crab, Callinectes sapidus Rathbun, 1896 (Brachyura, Portunidae) in the Neretva River delta (South-eastern Adriatic Sea, Croatia). Crustaceana (Leiden), 84, 1211. https://doi.org/10.1163/156854011X587478

Engel SR., Voshell J., 2002. Volunteer biological monitoring: Can it accurately assess the ecological condition of streams? American Entomologist 48:164-177 
Fuentes, M. A., Torrent, L., Barrera, S., Boix, D., 2019. Rapid invasion of the American blue crab Callinectes sapidus Rathbun, 1896 in the North-East of the Iberian Peninsula. Biolnvasions Record, 8.

Galil, B., Froglia, C. Noel, P.Y., 2002. CIESM Atlas of Exotic Species in the Mediterranean. Vol.2. Crustaceans: decapods and stomatopods. (F. Briand, Ed.), Monaco, CIESM Publishers, 192p

Garcia, L., Pinya, S., Colomar, V., París, T., Puig, M., Rebassa, M., Mayol, J., 2018. The first recorded occurrences of the invasive crab Callinectes sapidus Rathbun, 1896 (Crustacea: Decapoda: Portunidae) in coastal lagoons of the Balearic Islands (Spain). Biolnvasions Records, 7, 191-196.

Giovos, I., Kleitou, P., Poursanidis, D., Batjakas, I., Bernardi, G., Crocetta, F., Doumpas, N., Kalogirou, S., Kampouris, T.E., Keramidas, I. and Langeneck, J., 2019. Citizen-science for monitoring marine invasions and stimulating public engagement: a case project from the eastern Mediterranean. Biological Invasions, 21, 3707-3721.

Gökoðlu, N., Yerlikaya, P., 2003. Determinaton of proximate composition and mineral contents of blue crab (Callinectes sapidus) and swim crab (Portunus pelagicus) caught off the Gulf of Antalya. Food chemistry, 80, 495-498.

González-Ortegón, E., Jenkins, S., Galil, B.S., Drake, P. and Cuesta, J.A., 2020. Accelerated invasion of decapod crustaceans in the southernmost point of the Atlantic coast of Europe: A non-natives' hot spot?. Biological Invasions, 22(12), pp.3487-3492.

Gonzalez-Wanguemert, M., Pujol, J. A., 2016. First record of the atlantic blue crab Callinectes sapidus (Crustacea: Brachyura: Portunidae) in the Segura river mouth (Spain, southwestern Mediterranean Sea). Turkish Journal of Zoology, 40, 615-619.

Harding, J. M., 2003. Predation by blue crabs, Callinectes sapidus, on rapa whelks, Rapana venosa: possible natural controls for an invasive species?. Journal of Experimental Marine Biology and Ecology, 
Hines, A. H., Johnson, E. G., Young, A. C., Aguilar, R., Kramer, M. A., Goodison, M., ... Zohar, Y., 2008. Release strategies for estuarine species with complex migratory life cycles: stock enhancement of Chesapeake blue crabs (Callinectes sapidus). Reviews in Fisheries Science, 16, 175-185.

Hines, A. H., Lipcius, R. N., Haddon, A. M., 1987. Population dynamics and habitat partitioning by size, sex, and molt stage of blue crabs Callinectes sapidus in a subestuary of central Chesapeake Bay. Marine Ecology Progress Series, 36, 55-64.

Izquierdo-Gómez, D., Izquierdo-Muñoz., 2016. Evidence of the establishment of the American blue crab, Callinectes sapidus (Rathburn, 1896) in the Levantine coast of Spain (Western Mediterranean Sea). Karachle et al., New Mediterranean Biodiversity Records (March 2016) Mediterr. Mar. Sci., 17 (2016), pp. 232-233

Mancinelli, G., Carrozzo, L., Costantini, M. L., Rossi, L., Marini, G., Pinna, M., 2013. Occurrence of the Atlantic blue crab Callinectes sapidus Rathbun, 1896 in two Mediterranean coastal habitats: Temporary visitor or permanent resident?. Estuarine, Coastal and Shelf Science, 135, 46-56.

Mancinelli, G., Chainho, P., Cilenti, L., Falco, S., Kapiris, K., Katselis, G., Ribeiro, F., 2017a. On the Atlantic blue crab (Callinectes sapidus Rathbun 1896) in southern European coastal waters: Time to turn a threat into a resource?. Fisheries Research, 194, 1-8.

Mancinelli, G., Chainho, P., Cilenti, L., Falco, S., Kapiris, K., Katselis, G., Ribeiro, F., 2017b. The Atlantic blue crab Callinectes sapidus in southern European coastal waters: Distribution, impact and prospective invasion management strategies. Marine pollution bulletin, 119, 5-11.

McConaugha, J. R., Johnson, D. F., Provenzano, A. J., Maris, R. C., 1983. Seasonal distribution of larvae of Callinectes sapidus (Crustacea: Decapoda) in the waters adjacent to Chesapeake Bay. Journal of Crustacean Biology, 3, 582-591. 
Millot, C., Taupier-Letage, I., 2005. Circulation in the Mediterranean Sea. In The Mediterranean Sea (pp. 29-66). Springer, Berlin, Heidelberg.

Morais, P., Gaspar, M., Garel, E., Baptista, V., Cruz, J., Cerveira, I., ... Teodosio, M., 2019. The Atlantic blue crab Callinectes sapidus Rathbun, 1896 expands its non-native distribution into the Ria Formosa lagoon and the Guadiana estuary (SW-Iberian Peninsula, Europe). Biolnvasions Records, 8, 123-133.

Myers, N., Mittermeler, R. A., Mittermeler, C. G., Da Fonseca, G. A. Kents, J., 2000. Biodiversity hotspots for conservation priorities. Nature 403:853-858.

Nehring, S. 2011. Invasion history and success of the American blue crab Callinectes sapidus in European and adjacent waters. In In the wrong place-alien marine crustaceans: distribution, biology and impacts (pp. 607-624). Springer, Dordrecht.

Pezy, J. P., Raoux, A., Baffreau, A., Dauvin, J. C., 2019. A well established population of the Atlantic blue crab Callinectes sapidus (Rathbun, 1896) in the English Channel?. Cahiers de Biologie Marine, 60, 205209.

Prado, P., Peñas, A., Ibáñez, C., Cabanes, P., Jornet, L., Álvarez, N., Caiola, N., 2020. Prey size and species preferences in the invasive blue crab, Callinectes sapidus: Potential effects in marine and freshwater ecosystems. Estuarine, Coastal and Shelf Science, 245, 106997.

Ribeiro, F. and Veríssimo, A., 2014. A new record of Callinectes sapidus in a western European estuary (Portuguese coast). Marine Biodiversity Records, 7.

Shaiek, M., El Zrelli, R., Crocetta, F., Mansour, L., \& Rabaoui, L. (2020). On the occurrence of three exotic decapods, Callinectes sapidus (Portunidae), Portunus segnis (Portunidae), and Trachysalambria palaestinensis (Penaeidae), in northern Tunisia, with updates on the distribution of the two invasive portunids in the Mediterranean Sea. Biolnvasions Records, 10. 
Sharov, A. F., Vølstad, J. H., Davis, G. R., Davis, B. K., Lipcius, R. N., Montane, M. M., 2003. Abundance and exploitation rate of the blue crab (Callinectes sapidus) in Chesapeake Bay. Bulletin of Marine Science, 72, 543-565.

Siokou-Frangou, I., Christaki, U., Mazzocchi, M. G., Montresor, M., Ribera d'Alcalà, M., Vaqué, D., Zingone, A., 2010. Plankton in the open Mediterranean Sea: a review.

Sumer, C., Teksam, I., Karatas, H., Beyhan, T., Aydin, C. M., 2013. Growth and reproduction biology of the blue crab, Callinectes sapidus Rathbun, 1896, in the Beymelek Lagoon (Southwestern Coast of Turkey). Turkish Journal of Fisheries and Aquatic Sciences, 13, 675-684.

Streftaris, N., Zenetos, A., 2006. Alien marine species in the Mediterranean-the 100 'Worst Invasives' and their impact. Mediterranean Marine Science, 7, 87-118.

Tankersley, R. A., Wieber, M. G., Sigala, M. A., Kachurak, K. A., 1998. Migratory behavior of ovigerous blue crabs Callinectes sapidus: evidence for selective tidal-stream transport. The Biological Bulletin, 195, 168-173.

Templado, J., Gracia, F. J., Pérez Alberti, A., 2009. Introducción Grupo 1. Tipos de hábitat costeros y halofíticos.

Türkmen, A., Türkmen, M., Tepe, Y., Mazlum, Y., Oymael, S., 2006. Metal concentrations in blue crab (Callinectes sapidus) and mullet (Mugil cephalus) in Iskenderun Bay, Northern East Mediterranean, Turkey. Bulletin of Environmental Contamination \& Toxicology, 77.

US Congress, Office of Technology Assessment (OTA) 1993 Potential Environmental Impacts of Bioenergy Crop Production -- Background Paper. OTA-BP-E-118. US Government Printing Office, Washington, D.C., USA. 
Van Engel, W. A., 1990. Development of the reproductively functional form in the male blue crab, Callinectes sapidus. Bulletin of Marine Science, 46, 13-22.

Vasconcelos, P., Carvalho, A. N., Piló, D., Pereira, F., Encarnação, J., Gaspar, M. B., Teodósio, M. A., 2019. Recent and consecutive records of the Atlantic blue crab (Callinectes sapidus Rathbun, 1896): rapid westward expansion and confirmed establishment along the Southern Coast of Portugal. Thalassas: An International Journal of Marine Sciences, 35, 485-494.

Zotti, M., De Pascali, S. A., Del Coco, L., Migoni, D., Carrozzo, L., Mancinelli, G., Fanizzi, F. P., 2016. 1H NMR metabolomic profiling of the blue crab (Callinectes sapidus) from the Adriatic Sea (SE Italy): A comparison with warty crab (Eriphia verrucosa), and edible crab (Cancer pagurus). Food chemistry, 196, 601-609.

\section{Table}

Table 1 is available in the Supplementary Files.

\section{Figures}




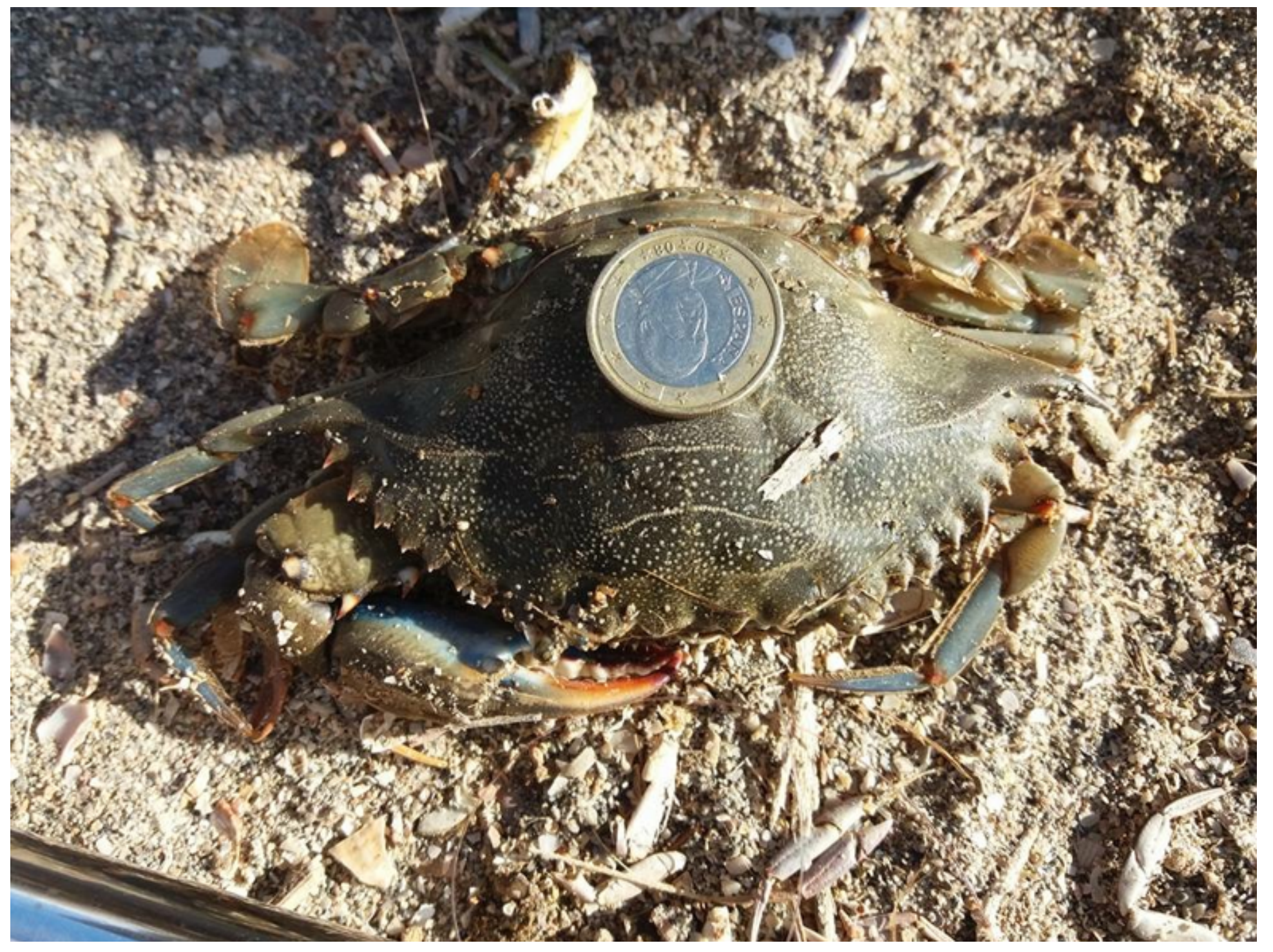

Figure 1

Photo of C. sapidus provided by recreational fishermen. 


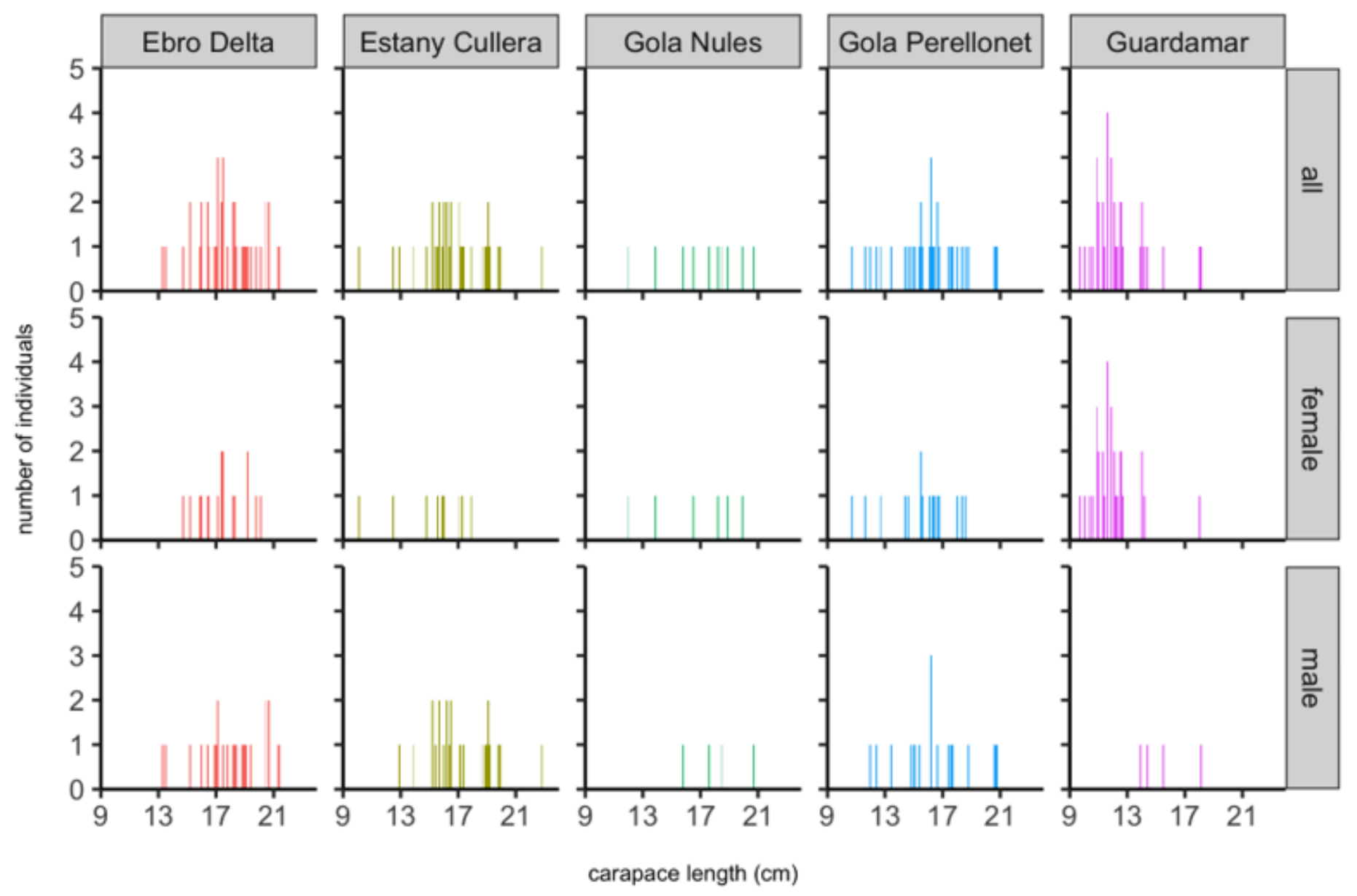

Figure 2

Carapace length distribution of Callinectes sapidus obtained through photographs sent by collaborators. 


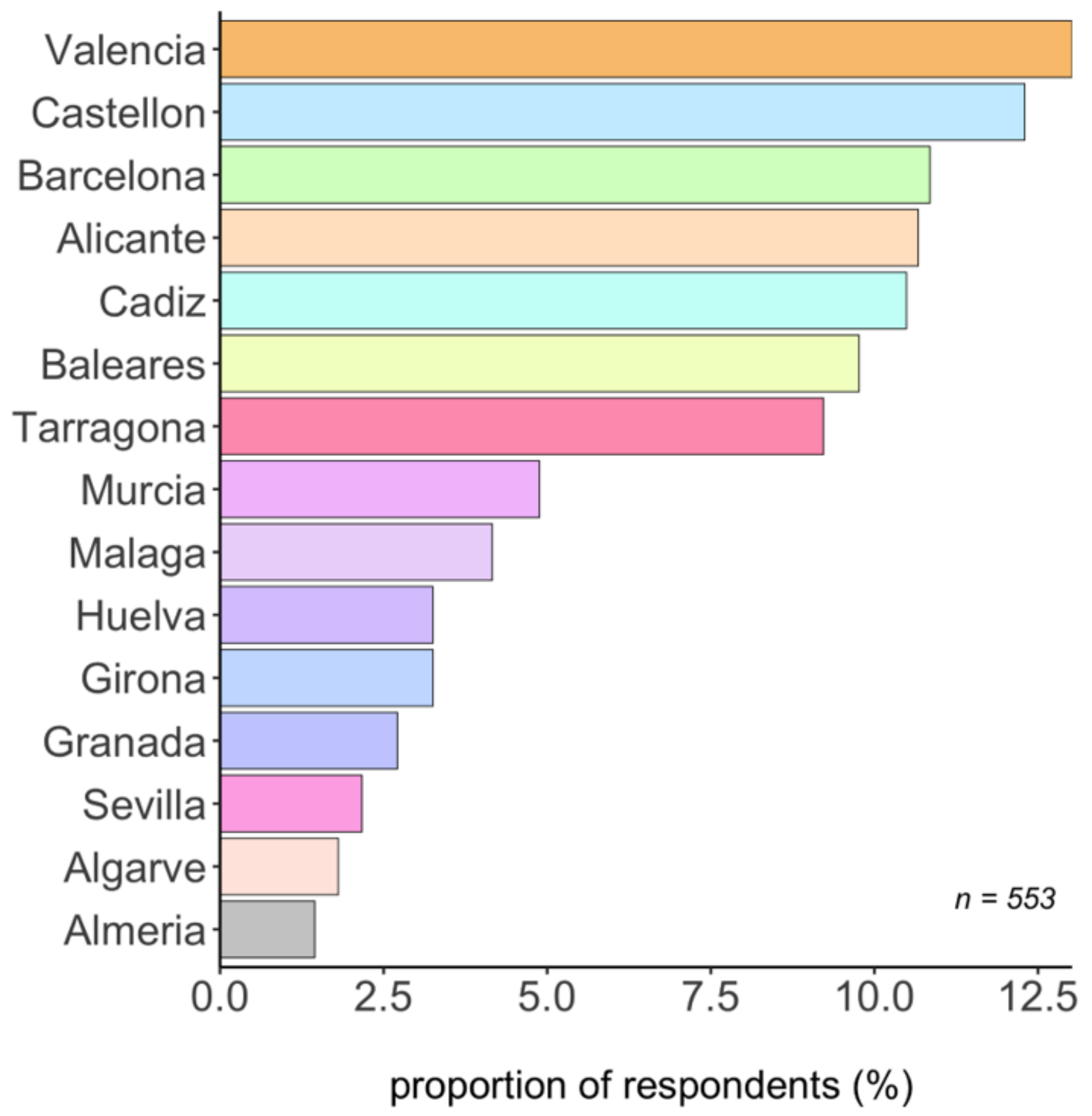

Figure 3

Bar plot depicting the frequency of respondents by province. 


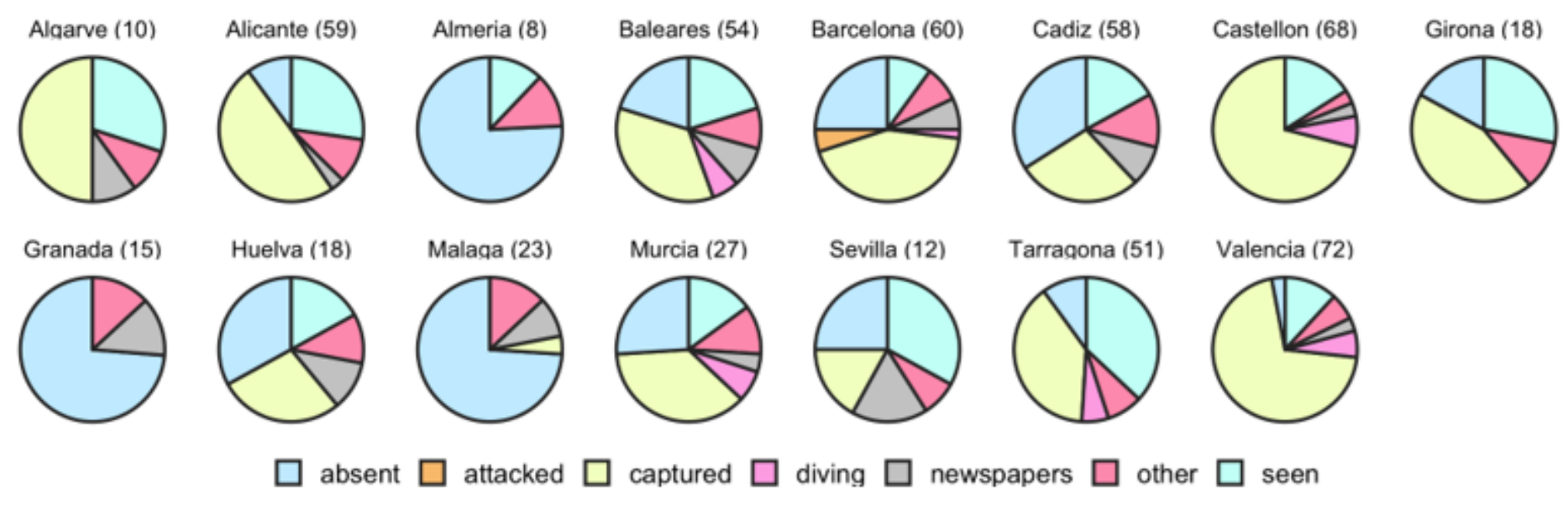

\section{Figure 4}

Pie charts showing the modality by which respondents aware of the presence of $\mathrm{C}$. sapidus in their fishing areas. Headers $=$ Province (number of respondents). 


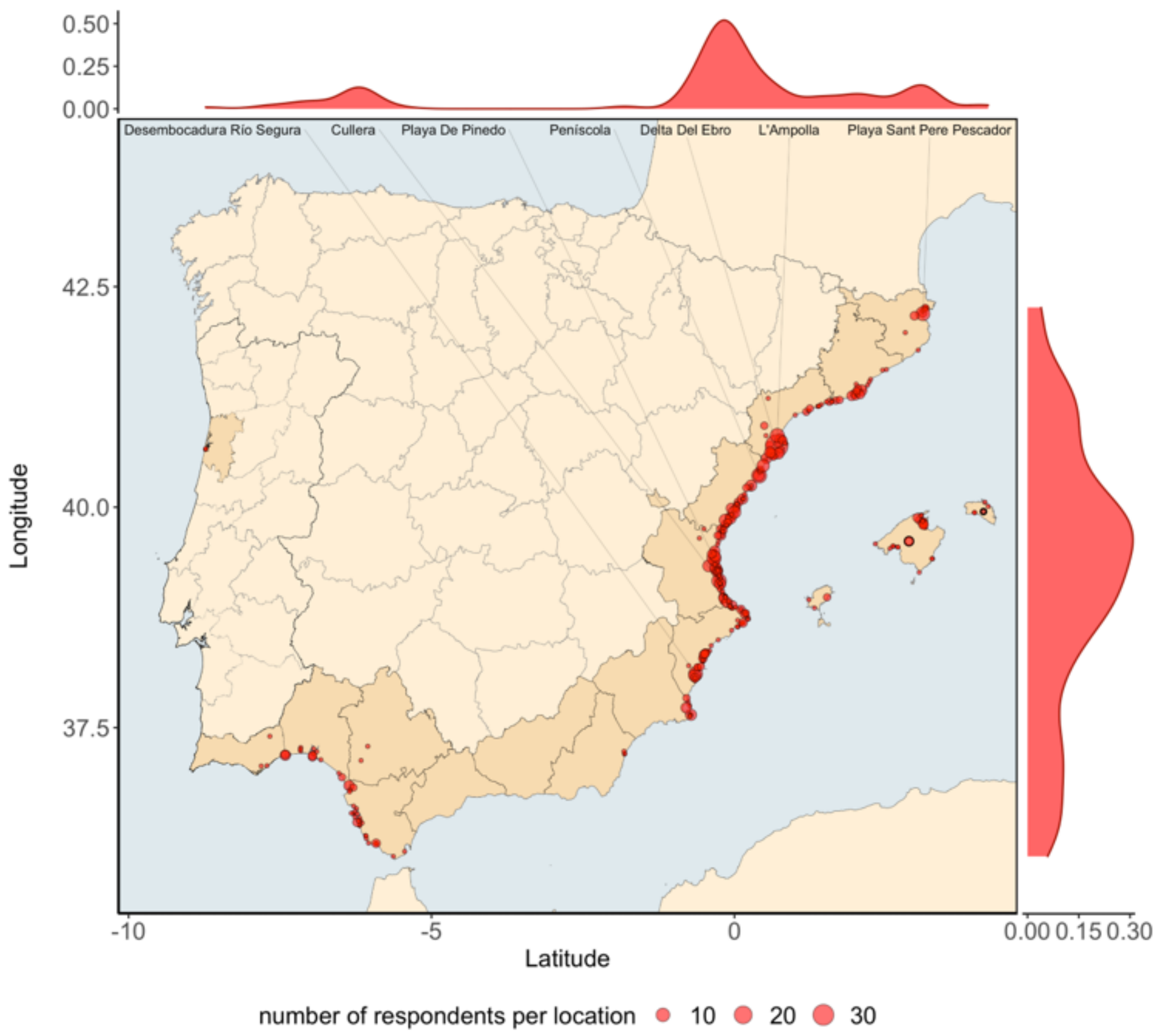

Figure 5

Spatial distribution of C. sapidus based on the comments of the respondents. Marginal density plots show the relative frequency of the origin of the respondents. Bubble size = number of respondents. Top text labels: the most frequent specific locations $(n>7)$. Bubbles located inland correspond to captures in brackish/freshwater areas (e.g. rivers, marshes). Inland circles with a thicker black contour represent participants, declaring unspecifically the presence of C. sapidus in Mallorca" (Lat: $39.61^{\circ} \mathrm{N}$; Lon: $2.88^{\circ} \mathrm{E}$ ) and Menorca (Lat:39.95 $\mathrm{N}$; Lon: $4.11^{\circ} \mathrm{E}$ ) respectively. 


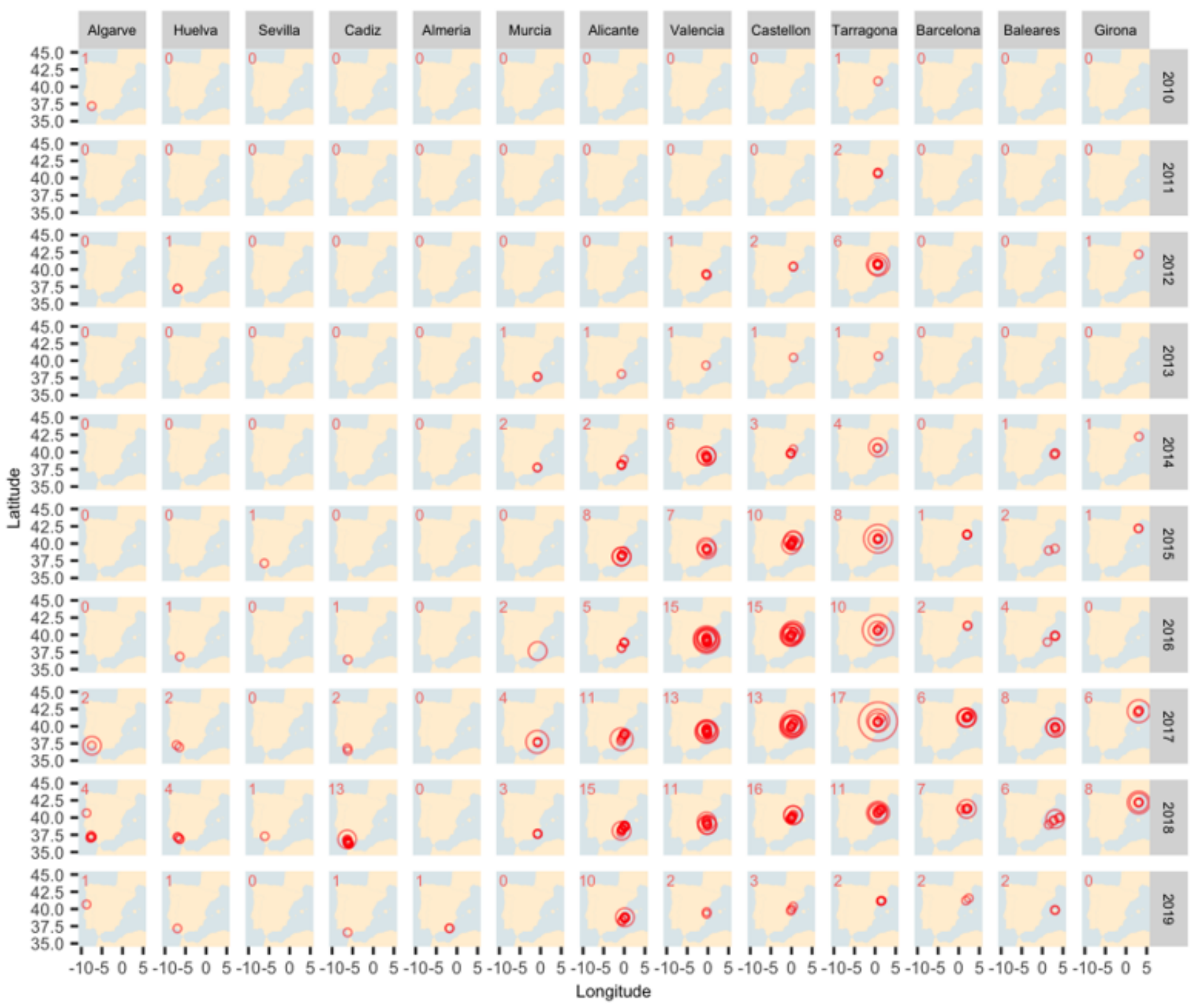

absolut frequency per location $\circ 1 \bigcirc 3 \bigcirc 5 \bigcirc 7 \bigcirc 10$

\section{Figure 6}

Spatio-temporal distribution of C. sapidus in the Iberian Peninsula within the period $2010-2019$. The top left number in maps represent the number of respondents contributing with information per year and province. The headers of the columns correspond to coastal provinces geographically aligned from south-west to north-east, to ease the dispersion pattern of the blue crab in the figure. For sake of figure simplicity, Algarve region contains also respondents from Aveiro region. 


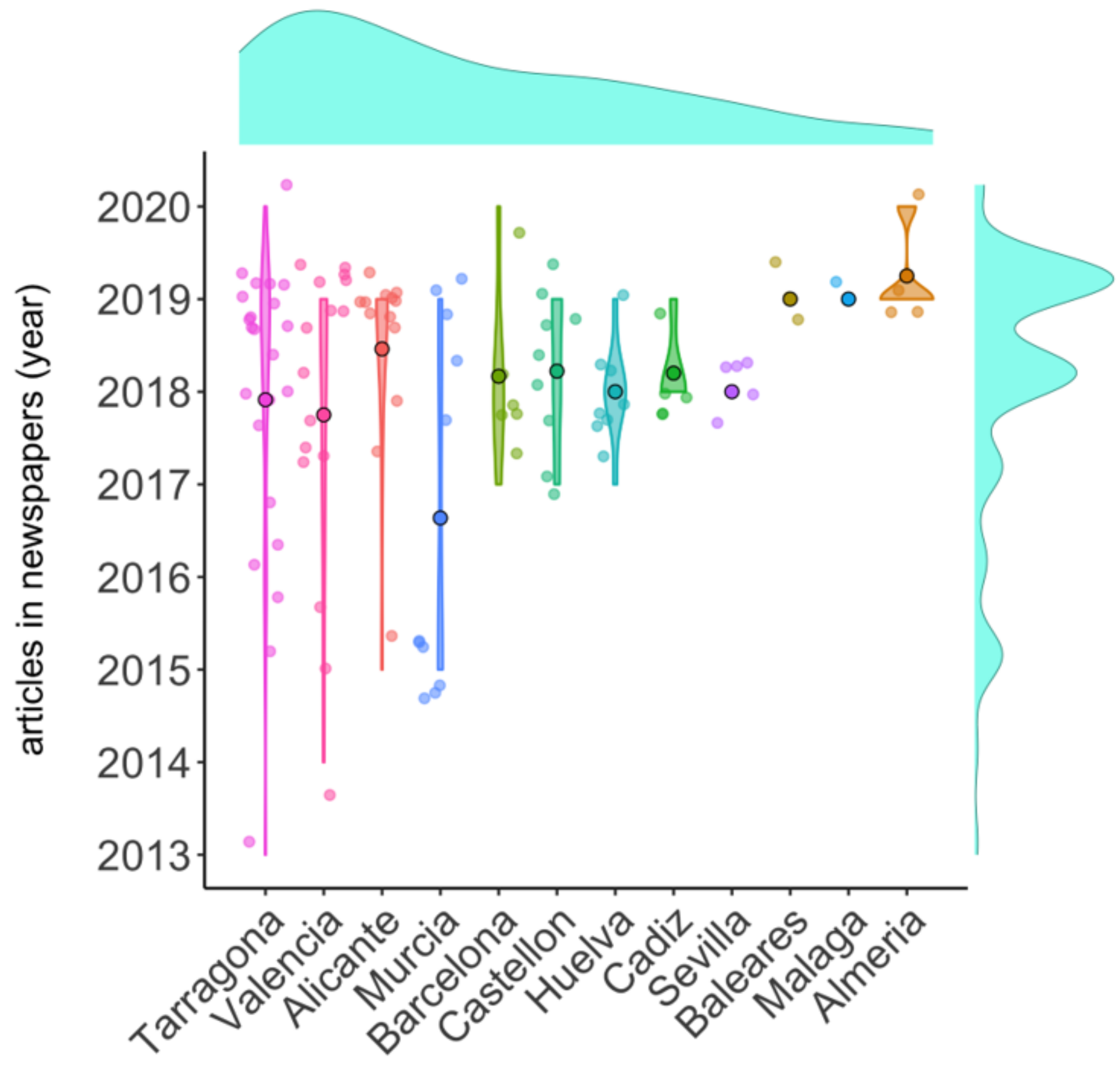

Figure 7

Temporal distribution of C. sapidus articles published in local newspapers at a province level. Circles indicate the average year values. 


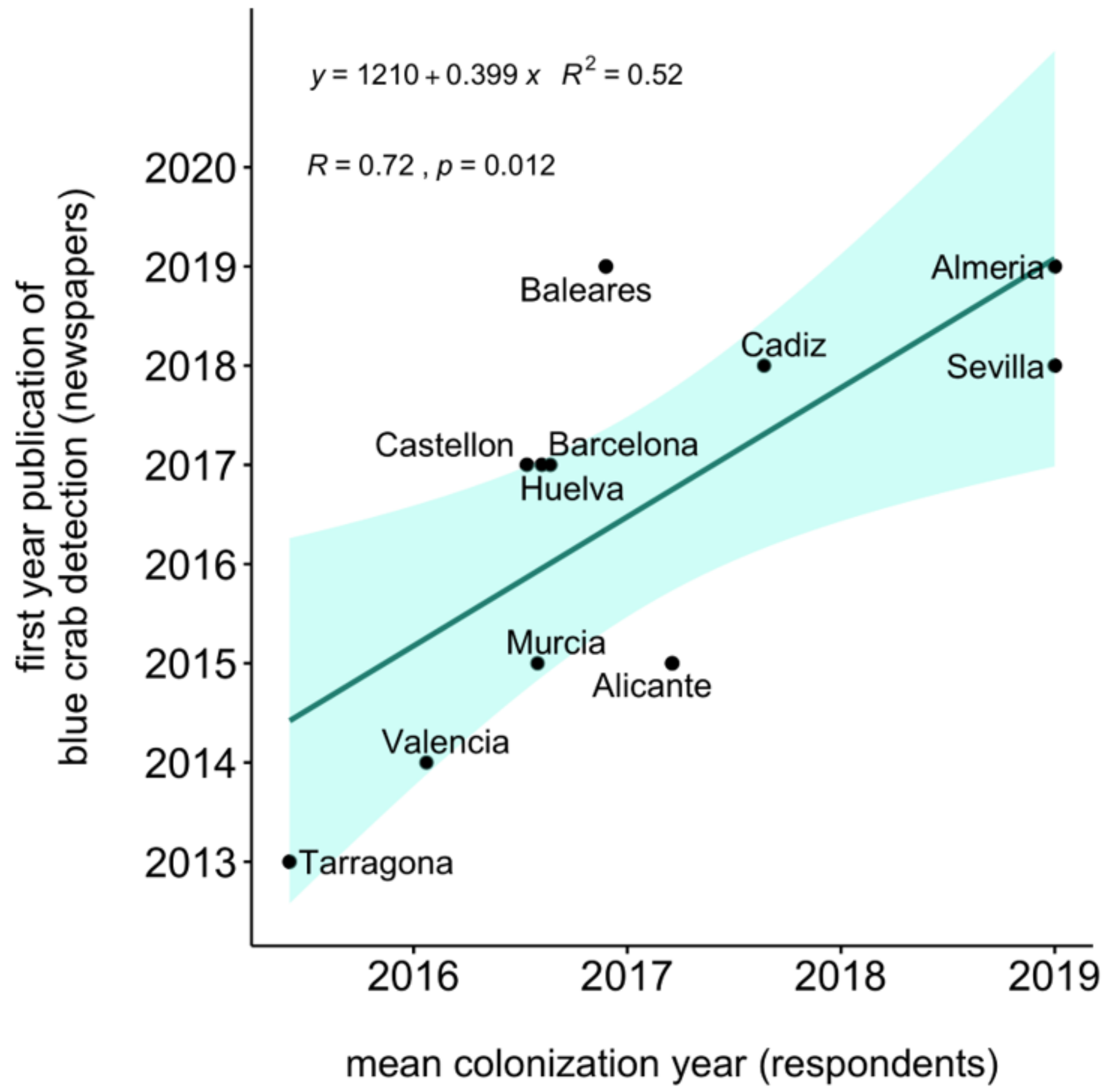

Figure 8

Correlation between the mean colonization year declared by respondents, and the first-year publication covering the presence of $\mathrm{C}$. sapidus in local newspapers. 


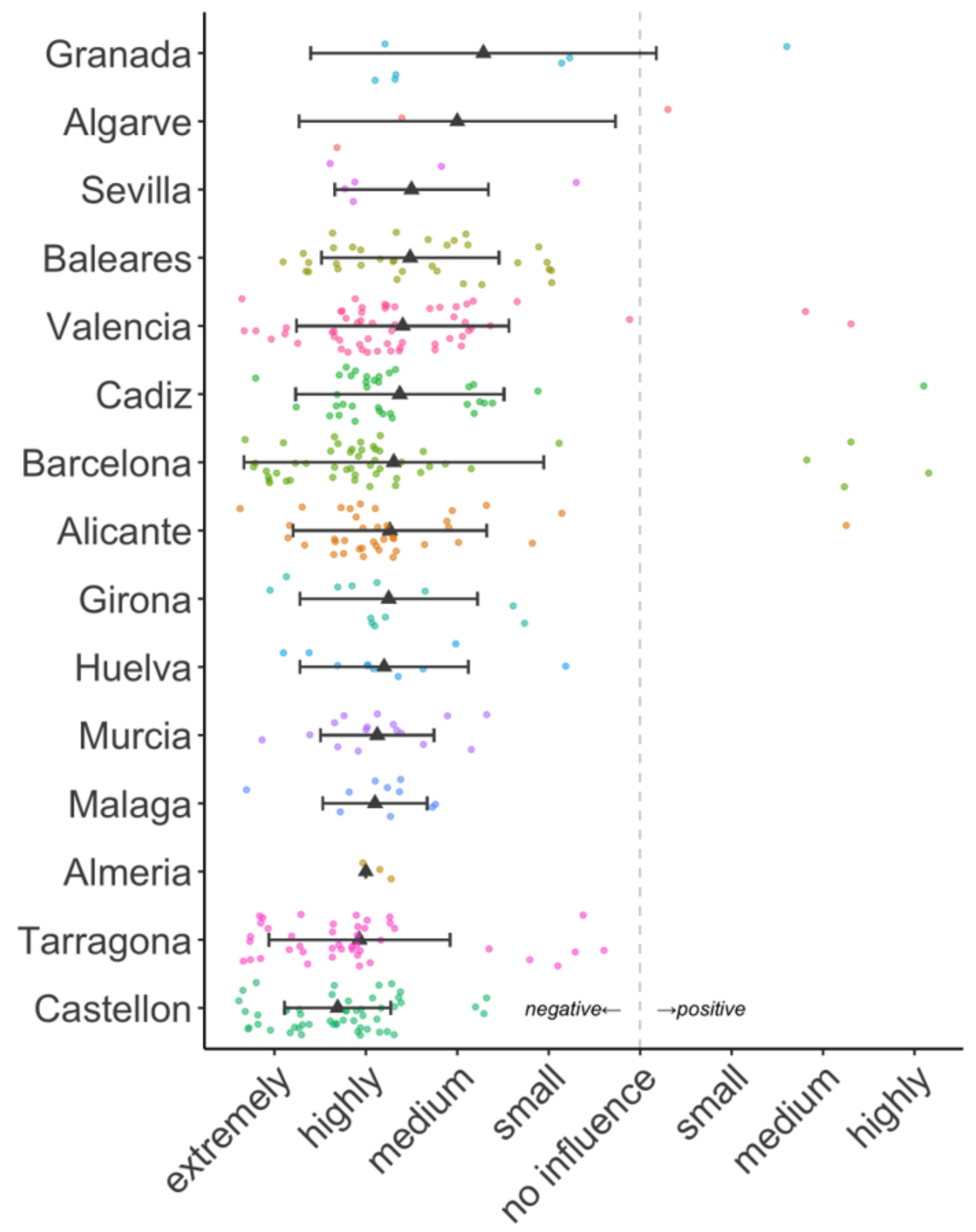

Figure 9

Perception of fishermen on the ecological consequences of the blue crab invasion. $\boldsymbol{\Delta}=$ mean value \pm standard deviation. In the $x$ axis, different colours represent different provinces. Left hand side of the dash line = negative scores; right hand side of the dash line = positive scores; Dash line = neutral score.

\section{Supplementary Files}


This is a list of supplementary files associated with this preprint. Click to download.

- Tables.docx

- Annex.docx 